This is the peer reviewed version of the following article: Cameron, D., Harris, F. M. and Evans, J. M. M. (2016), Patterns of self-monitoring of blood glucose in insulin-treated diabetes: analysis of a Scottish population over time. Diabetes, Obesity and Metabolism, 18: 729-731. doi:

10.1111/dom.1266, which has been published in final form at

http://onlinelibrary.wiley.com/doi/10.1111/dom.12662/abstract. This article may be used for noncommercial purposes in accordance With Wiley Terms and Conditions for self-archiving. 


\section{Patterns of self-monitoring of blood glucose (SMBG) in insulin-treated diabetes: analysis of a Scottish population over time.}

Dawn Cameron, School of Health Sciences, University of Stirling, Stirling, FK9 4LA.

PhD Student.

Fiona M Harris, Nursing, Midwifery and Allied Health Professionals Research Unit, University of Stirling, FK9 4NF

Senior Lecturer

Josie MM Evans, School of Health Sciences, University of Stirling, Stirling, FK9 4LA.

Reader in Public Health

Corresponding author:

Dawn Cameron

School of Health Sciences

University of Stirling

Stirling

FK9 4LA

Tel no: +44 1786466352

Fax no: +44 1786466333

E mail: dawn.cameron@stir.ac.uk

Running title: Self-monitoring of blood glucose in insulin-treated diabetes 


\begin{abstract}
Analysis of a diabetes clinical information system in Tayside, Scotland, shows that a significant proportion of insulin-treated patients with diabetes are not self-monitoring blood glucose according to current clinical guidance and recommendations, with some not self-monitoring their blood glucose at all. Although there has been an increase in the numbers of reagent strips dispensed over the past decade, this increase is mainly accounted for by increased testing frequency among people with diabetes already testing.
\end{abstract}

\title{
Introduction
}

Self-monitoring of blood glucose (SMBG) is fundamental to diabetes self-management for people with type 1 diabetes and those with type 2 diabetes treated with insulin $(1,2)$ with an important role to play in the prevention of hypoglycaemia and in the reduction of longer-term complications. Current guidance recommends routine SMBG in type 1 diabetes; at least four times per day and possibly even up to ten times daily, with frequency and timing individualized to the patient (1-3). Guidance for type 2 diabetes suggests that routine testing should be undertaken by people treated with insulin (1,4-6) and anyone at particular risk of hypoglycaemia.

Studies have shown a general increase in self-monitoring over the past two decades in the UK and elsewhere $(7,8)$. Frequency of testing has increased alongside increases in the numbers of those testing. A study in Scotland identified an increase in the proportion of all people with type 2 diabetes carrying out any SMBG from $15.5 \%$ in 1993 to $29.8 \%$ in 2009 (7). However, it is perhaps more important to assess the level of testing in patient groups for whom regular testing is specifically recommended. We therefore used a record-linkage diabetes clinical information system in Tayside, Scotland, to investigate patterns and levels of self-monitoring among people with type 1 diabetes and those with type 2 diabetes who are treated with insulin.

\section{Methods}


The Health Informatics Centre, University of Dundee $(9,10)$ uses the record-linkage of health care data to facilitate epidemiological and health services research in Scotland. Recordlinkage is enabled by the widespread use of a unique health care identifier ( $\mathrm{CHI}$ number) that is allocated to people when they register with a General Practitioner (GP) in Scotland. SCI-DC (Scottish Care Information - Diabetes Collaboration) is a validated population-based diabetes information system, compiled by record-linking several independent data sources [6]. Detailed clinical information is available via SCI-DC for all people with diabetes. There are also computerised records of prescriptions dispensed, including those for self-monitoring equipment to residents of the region of Tayside, (current estimated population is 412,160 ). These are free of charge so almost everyone with diabetes is likely to obtain their reagent strips via this route.

People in Tayside with either type 1 or type 2 diabetes, who were dispensed at least one prescription of insulin during that year were identified for the period 2004 to 2011 . The total numbers of SMBG reagent strips dispensed to them were calculated from information on the prescription. A cross-sectional analysis of a 3 year period 1/1/2009 - 31/12/20011 was also undertaken. We investigated whether SMBG patterns were associated with age, sex and a postcode measure of material deprivation that classified people into quintiles of deprivation (according to information on income, employment, health and disability, education, skills, and training and access to services for small geographical areas) [6]. Proportions testing within sub-groups and the median number of strips dispensed in the 3-year period were also determined.

\section{Results}


The overall numbers of SMBG reagent strips dispensed has almost doubled over time, from 833,500 strips dispensed to 1,225 people with type 1 diabetes in 2004, to 1,547,950 strips dispensed to 1,573 people in 2011. Similarly, in type 2 diabetes, numbers of SMBG strips dispensed increased from 950,400 dispensed to 1,830 people treated with insulin in 2004 to 1,416,200 dispensed to 2,473 people in 2011 (Table 1).

The proportion of people with type 1 diabetes who received any strips increased from $72 \%$ in 2004 to $80 \%$ in 2011 , suggesting that there are still around one in five who are not testing at all. The approximate doubling in the number of strips dispensed over time can be attributed almost equally to increased numbers of people testing, and to increased frequency among those already testing (as shown by an increase in the median number of strips dispensed). In contrast, in type 2 diabetes, the proportion who test has remained relatively stable over the study period; $88 \%$ in 2004 and $91 \%$ in 2011 . The large increase in the overall number of strips dispensed is therefore accounted for by increases in testing frequency among those who already test, rather than being an indication of wider engagement with SMBG. Despite this, many people are still not receiving enough strips to test more than once or twice daily, although testing frequency is higher in type 1 diabetes.

Table 2 shows that between 2009 and 2011, women were more likely to test, and people with type 1 diabetes were testing more frequently. There was an effect of deprivation on frequency of testing, with people living in less deprived areas testing more frequently than those living in more deprived areas. In general, testing frequency increased with age but the proportion of older people (70+ years) doing any testing with type 2 diabetes was particularly low. 


\section{Discussion}

Despite a body of evidence identifying the importance of SMBG in maintaining glycaemic control and in turn decreasing the risk of diabetic related complications $(6,10)$, around 10 $20 \%$ of people with type 1 and type 2 diabetes who are treated with insulin are not testing at all. This level of non-testing has remained stable over the last decade. Furthermore, testing is not carried out as frequently as recommended within both patient groups. These low levels of testing are worrying given the importance of SMBG in the prevention of hypoglycaemia, and possible implications for behaviours such as driving. There is also evidence that SMBG may be associated with reductions in diabetes-related complications. These findings therefore have significant implications for health costs for individual people and health services. (10-12).

The effect of deprivation on frequency of testing has been noted by several authors, in particular in type 2 diabetes, and is a concern given its potential to widen inequalities in diabetes outcomes $(7,13-16)$. It is important that everyone who is treated with insulin and for whom SMBG may be beneficial has appropriate knowledge surrounding testing recommendations and the practice of self-monitoring (16)..

The strengths of this study are its population-based approach and the use of a validated diabetes clinical information system, with records of dispensed prescriptions for reagent strips. However, we cannot be sure that people necessarily used the reagent strips that were dispensed to them; neither can we be sure that some did not receive strips from other sources. The study does identify a need for a deeper understanding of why people are not self-monitoring in line with current guidance. There is a need to investigate further how people are testing and as well as influences on testing behaviours.

\section{Competing Interests}

Nothing to declare

\section{Acknowledgements}

We acknowledge the Health Informatics Centre, University of Dundee for the provision of data. This study was part funded by Lifescan, Scotland, Ltd, The researchers were independent from the funding body. 


\section{REFERENCES}

1. Scottish Intercollegiate Guidelines Network. 116 Management of Diabetes: a national clinical guideline. 2010. http://www.sign.ac.uk/pdf/sign116.pdf. Accessed 4/4/2016.

2. Reynolds R., Webb D. Recommendations and conclusions from a mini-symposium on self-blood glucose monitoring. J R Coll Physicians Edinb. 2006;36:155-8.

3. National Institute of Health Care and Excellence. Type 1 diabetes in adults : diagnosis and management. NICE Guideline. 2015. https://www.nice.org.uk/guidance/ng17. Accessed 4/4/2016.

4. Hansen M V, Pedersen-Bjergaard U, Heller SR, Wallace TM, Rasmussen a K, Jørgensen $\mathrm{H} \mathrm{V}$, et al. Frequency and motives of blood glucose self-monitoring in type 1 diabetes. Diabetes Res Clin Pract.2009; 85(2):183-8

5. Nomura DM. Importance of using and understanding self-monitoring of blood glucose (SMBG) data in assessing ambient and long-term glycaemic control. J Indian Med Assoc [Internet]. Lifescan Inc, California, USA.: Indian Medical Association : Calcutta; 2002;100(7):448.

6. Montagnana M, Caputo M, Giavarina D, Lippi G. Overview on self-monitoring of blood glucose. Clin Chim Acta.2009;402(1-2):7-13.

7. Evans JMM, Mackison D, Emslie-Smith A, Lawton J. Self-monitoring of blood glucose in Type 2 diabetes: cross-sectional analyses in 1993, 1999 and 2009. Diabet Med 2012; 29,(6):792-5.

8. Pan L, Mukhtar Q, Geiss LS. Self-Monitoring of Blood Glucose Among Adults with Diabetes--United States, 1996-2005. Diabetes. 2007 Feb;56:A257-A257.

9. Scottish Government, Using the Scottish Index of Multiple Deprivation, Guidance leaflet, 2006 . http://www.gov.scot/Publications/2006/10/13142841/1. Accessed $4 / 4 / 2016$

10. St John A, Davis W, Price CP, Davis TME. The value of self-monitoring of blood glucose: a review of recent evidence. J Diabetes Complications.; 2010;24(2):129-41.

11. O'Kane MJ, Pickup J. Self-monitoring of blood glucose in diabetes: is it worth it? Ann Clin Biochem. 2009;46(Pt 4):273-82.

12. Belsey JD, Pittard JB, Rao S, Urdahl H, Jameson K, Dixon T. Self blood glucose monitoring in type 2 diabetes. A financial impact analysis based on UK primary care. Int J Clin Pract. 2009;63(3):439-48.

13. Kjome RLS, Granas AG, Nerhus K, Roraas TH, Sandberg S. The Prevalence of SelfMonitoring of Blood Glucose and Costs of Glucomenter Strips in a Nationwide Cohort. Diabetes Technol \& Ther. 2010;12(9):701-5.

14. Secnik K, Yurgin N, Lage MJ, McDonald-Everett C. Patterns of blood glucose monitoring in relation to glycemic control among patients with type 2 diabetes in the UK. J Diabetes Complications. 2007;21(3):181-6.

15. Jaworska J, Dziemidok P, Kulik TB, Rudnicka-Drozak E. Frequency of self-monitoring and its effect on metabolic control in patients with type 2 diabetes. Ann Univ Mariae Curie-SkłodowskaSectio D Med. 2004;59(1):310-6. 
16. Abbott S, Burns J. Community nurses and self-monitoring of blood glucose. British Journal of Communicty Nursing. 2007;12(1).

TABLES 
Table 1: Numbers of SMBG reagent strips dispensed by year and the number of patients with any strips dispensed

\begin{tabular}{|l|l|l|l|l|l|l|l|l|}
\hline Year & \multicolumn{5}{|c|}{ Type 1 diabetes } & \multicolumn{4}{c|}{ Type 2 diabetes } \\
\hline & $\begin{array}{c}\text { No. of } \\
\text { patients }\end{array}$ & $\begin{array}{c}\text { No. of } \\
\text { strips } \\
\text { dispensed } \\
\text { patients with } \\
\text { strips } \\
\text { dispensed }\end{array}$ & $\begin{array}{c}\text { Median } \\
\text { no. of } \\
\text { strips } \\
\text { dispensed } \\
\text { per day }\end{array}$ & $\begin{array}{c}\text { No. of } \\
\text { patients }\end{array}$ & $\begin{array}{c}\text { No. of } \\
\text { strips } \\
\text { dispensed }\end{array}$ & $\begin{array}{c}\text { No. (\%) of } \\
\text { patients } \\
\text { with strips } \\
\text { dispensed }\end{array}$ & $\begin{array}{c}\text { Median } \\
\text { no. of } \\
\text { strips } \\
\text { dispense } \\
\text { d per } \\
\text { day }{ }^{1}\end{array}$ \\
\hline 2004 & 1698 & 833500 & $122572 \%$ & 1.4 & 2073 & 950400 & $183088 \%$ & 1.1 \\
\hline 2005 & 1712 & 882250 & $146485 \%$ & 1.2 & 2125 & 1096300 & $193491 \%$ & 1.2 \\
\hline 2006 & 1802 & 1100200 & $137676 \%$ & 1.6 & 2273 & 1201350 & $206591 \%$ & 1.2 \\
\hline 2007 & 1845 & 536000 & $120765 \%$ & 0.8 & 2228 & 1018100 & $195288 \%$ & 1.1 \\
\hline 2008 & 1882 & 648450 & $117964 \%$ & 1.0 & 2246 & 1006555 & $195987 \%$ & 1.1 \\
\hline 2009 & 1951 & 810900 & $133768 \%$ & 0.5 & 2466 & 1236950 & $217688 \%$ & 1.2 \\
\hline 2010 & 1946 & 1432100 & $155480 \%$ & 1.9 & 2597 & 1352100 & $233790 \%$ & 1.2 \\
\hline 2011 & 1969 & 1574950 & $157380 \%$ & 2.2 & 2718 & 1416200 & $247391 \%$ & 1.4 \\
\hline${ }^{1}$ Among patients with any strips dispensed & & & & & \\
\hline
\end{tabular}

Table 2: Numbers of SMBG reagent strips dispensed and numbers of patients receiving strips, stratified by gender, age and deprivation

\begin{tabular}{|l|l|l|l|l|l|l|l|l|}
\hline Attribute & \multicolumn{3}{|c|}{ Type 1 diabetes } & \multicolumn{3}{c|}{ Type 2 diabetes } \\
\hline & $\mathrm{N}$ & $\begin{array}{l}\text { No. } \\
\text { of } \\
\text { patie }\end{array}$ & $\begin{array}{l}\text { \% of } \\
\text { patients }\end{array}$ & $\begin{array}{l}\text { Median } \\
\text { no. of } \\
\text { strips }\end{array}$ & $\mathrm{N}$ & $\begin{array}{l}\text { No. of } \\
\text { patients }\end{array}$ & $\begin{array}{l}\text { \% of } \\
\text { patients }\end{array}$ & Median \\
\hline
\end{tabular}




\begin{tabular}{|c|c|c|c|c|c|c|c|c|}
\hline & & $\begin{array}{l}\text { nts } \\
\text { with } \\
\text { strips } \\
\text { dispe } \\
\text { nsed }\end{array}$ & $\begin{array}{l}\text { with strips } \\
\text { dispensed }\end{array}$ & $\begin{array}{l}\text { dispensed } \\
\text { per day }{ }^{1}\end{array}$ & & $\begin{array}{l}\text { with strips } \\
\text { dispensed }\end{array}$ & $\begin{array}{l}\text { with strips } \\
\text { dispensed }\end{array}$ & $\begin{array}{l}\text { no. of strips } \\
\text { dispensed } \\
\text { per day }{ }^{1}\end{array}$ \\
\hline \multicolumn{9}{|l|}{ Gender } \\
\hline Female & 818 & 738 & $90 \%$ & 1.8 & 941 & 872 & $93 \%$ & 1.0 \\
\hline Male & 982 & 845 & $86 \%$ & 1.4 & 1053 & 950 & $90 \%$ & 1.1 \\
\hline \multicolumn{9}{|l|}{ Age } \\
\hline $113-24$ & 408 & 362 & $89 \%$ & 1.4 & 4 & 4 & $100 \%$ & 0.3 \\
\hline $225-40$ & 539 & 451 & $84 \%$ & 1.1 & 70 & 56 & $80 \%$ & 0.5 \\
\hline $341-55$ & 545 & 483 & $89 \%$ & 1.6 & 377 & 338 & $90 \%$ & 0.7 \\
\hline $456-70$ & 233 & 218 & $94 \%$ & 2.1 & 848 & 789 & $93 \%$ & 1.0 \\
\hline $570+$ & 75 & 69 & $92 \%$ & 2.4 & 694 & 534 & $77 \%$ & 1.4 \\
\hline \multicolumn{9}{|c|}{ Deprivation quintile } \\
\hline $\begin{array}{l}\text { 1(most } \\
\text { deprived) }\end{array}$ & 324 & 287 & $89 \%$ & 1.2 & 448 & 412 & $92 \%$ & 0.9 \\
\hline 2 & 364 & 312 & $86 \%$ & 1.3 & 426 & 392 & $92 \%$ & 0.9 \\
\hline 3 & 342 & 308 & $90 \%$ & 1.7 & 394 & 357 & $91 \%$ & 1.2 \\
\hline 4 & 389 & 334 & $86 \%$ & 1.8 & 373 & 341 & $91 \%$ & 1.0 \\
\hline $\begin{array}{l}5 \text { (least } \\
\text { deprived) }\end{array}$ & 312 & 284 & $91 \%$ & 1.9 & 307 & 292 & $92 \%$ & 1.2 \\
\hline
\end{tabular}

